Letras, Lima. 1977-79. (Nos. 86-87), 109-120.

\title{
Moral, causalidad e ironía en la narrativa de Vargas Llosa
}

MIGUEL VALLE

Las estructuras de pensamiento que combaten en el interior del creador con el libre juego de la fantasía y del recuerdo traen consigo sedimentaciones del pasado, como memoria, tradición e interpretación. Los problemas filosóficos y culturales se desabstractifican en la obra de arte, que no es simple experiencia inmediata, sino síntesis existencial y cultural. Por eso mismo, el estado de una determinada sociedad no es un elemento accesorio ni para la comprensión de la obra de arte ni para la forma en que ésta se configura. Viceversa, la obra señala, con sus repeticiones y silencios, los puntos débiles de un cuerpo social. Rastrear determinadas temáticas es investigar tearencias y áspiraciones. No siempre es tarea fácil, puesto que la carencia principal de numerosas sociedades es la de libertad.

Tampoco es necesario que una obra literaria sea directamente crítica, en el sentido comúnmente aceptado. Su criticidad debe ser establecida partiendo de los criterios específicos del ámbito estético. La hermenéutica de lo artístico no puede aplicar mecánicamente las reglas de los lenguajes naturales y científicos. $O$, también, es posible decir que se impone una ampliación del concepto de criticidad; la obra de arte sería, en esta suposición, esencialmente crítica, en cuanto desplazaría contenidos inaceptables y propondría una nueva lectura de lo real: sin negar necesariamente las anteriores. Así, por ejemplo, Tres tristes tigres, de Cabrera Infante, es menos noctambulismo inquisitorial que defensa de las semánticas particulares. Paradiso, de Lezama Lima, demuestra que la crítica no es algo añadido desde el exterior a la realidad, sino una dimensión de ésta. De todos modos, el contenido crítico de una obra y, con mayor razón, de la.producción de un autor, incluye necesariamente un juego entre concepciones fundamentales de la realidad, de cuyo movimiento dialéctico brota no sólo la 
acción sino también la explicación de la elección de determinados hechos. En un plano más restringido, el contenido crítico surge de la dinámica que se establece entre categorías interoretativas de la realidad. En esta nota queremos referirnos a tres de ellas; las categorías de moralidad, causalidad e ironía, como se presentan en la narrativa de Mario Vargas Llosa.

\section{El moralismo como destrucción de la moral.}

Las obras de arte exigen ser recibidas por un apriori estético libre de rigidez: la introducción de la historicidad en las mismas estruciuras conoscitivas ha permitido no sólo abandonar la suposición de un sujeto absoluto, sino también el privilegio que derivaba de allí a los sujetos empíricos que for particulares circunstancias ya se encontraban en una situación más favorable. El abriori estético se transformaba allí en un factor sectoriai del conocimiento humano y, a la larga, se provincializaba. Esto no significa, sin embargo, que el apriori sea legítimo simplemente por constituir la propia recepción de la obra de arte. Es necesario, en cierto modo, modificarlo, para hacer justicia cabal a la obra, para permitirle ser tal. Es obvio que hay aquí un contiruo movimiento dialéctico que incluye la propia situación conoscitiva, la comprensión de las diversas y sucesivas concretizaciones del texto o de la obra de arte y los resuliados sociales $u$ objetivos de la comprensión, más - menos colectiva, de la obra en cuestión.

Aquí queremos limitarnos a señalar la insuficiencia de la clave moralista para la comprensión dela obrate arte y, en concreto, de la producción novelística de Vargas Llosa. Nos parece que un apriori moralístico destruiría no sólo su expresividad artística sino aun sus contenidos conceptuales, teóricos y emocionales. Más aún, nos apoyamos en la idea de que el moralismo constituye no sólo un atentado contra la consistencia del ámbito moral, sino que llega a destruirlo, neutralizándolo y desvalorizándolo. El moralismo devora el auténtico campo de juego de lo moral pretendiendo extender la caracidad de la libertad hasia el ineludible reino de los determinismos. Su confianza en la omnipotencia de la voluntad termina obstaculizando cualquier acción realista y eficaz, y no logra evitar que el fracaso se trasforme en autodesprecio. No nos parece exagerado afirmar aquí, como hipótesis, que una de las fuenies principales de la ironía latinoamericana es un desmedido moralismo, que deriva a su vez de la carencia de contrapesos al predominio de las filosofías idealisias, espiritualistas y personalistas que han ocupado el panorama intelectual de América Latina. Prima, ante todo, la confianza en la potencia de la voluntad, por más que luego la confusión sobre la fuerza de los determinismos lleve a interpretar cualquier derrota con categorías autolesivas. En 
el moralismo se desencadena un movimisnto pendular, que va de la euforia al abatimiento, del sentimiento de triunfo a la depresión, de la presurición a la vergüenza de sí mismo. El menosprecio de los elementos objetivos de la realidad reduce las vicisitudes del individuo a un juego de sentimientos y de actos de valor o cobardía. El moralismo puede enmascararse aun en su contrario, en el espíritu vclteriano y en el escepticismo jocoso. Una clave moralista lleva inevitablemente a desfigurar las dimensiones reales de la obra de arte. Si leemos en clave moralista El Señor Presidente, de Asturias, o El otoño del patriarca, de García Márquez, no sólo se hace incomprensible el proceso cée cicumulación de poder, sino que la obra queda reducida a un panfleto difamatorio del pueblo que produce o tolera tales engendros. Despojadas de su marco social y reducidas a formato puramente individual, Persona non grata, de Jorge Edwards, o El caso Banchero, de Guillermo Thorndike, se transforman en crónica maldiciente.

¿Cómo podría explicarse en clave moralista la particular complejidad estructural de Conversación en la Catedral o de La Casa Verde? El moralismo no constituye una baso suficiente para justificar procedimientos analítices. A lo más, apoyaría recursos puramente cuantitativos, en que se debería trazar, descriptivamente, una línea divisoria y definitiva entre los 'buenos', por una parte, y los 'malos', por otra. Es obvio que este modo de proceder destruiría la consistencia de la obra de arte y aquella progresividad hacia valores futuros que provoca su aparente 'ambigüedad', la pluralidad de interpretaciones posibles y los conflicios con los sistemas ideológicos y Bolíticost cuya aspiración gnoseológica (y condición de subsistencia) es la claridad y la univocidad.

En las obras de Vargas Llosa existen multiples elementos que permiten 'secuperar', en ciertos personajes, una dimensión moral que contrapesa parcialmente el recharo que provoca el conjunto de la descripción y que, por tanto, rompen la posibilidad de una interpretación moralística. En Conversación en la Catedral don Fermín Zavala, aun en medio de sus vergonzosas debilidades y y de oportunismo, tiene rasgos de profunda humanidad como padre, y hasta de comprensión hacia lo que atenia contra su propia clase social. Las turbulentas discusiones familiares muestran na sólo su equilibrio y sentido de la justicia sino que (desgraciadamente para el futuro) está más 'a la izquierda' que su mujer y sus hijos, el Chispas y la Teté, internalizadores furiosos de los valores hurgueses (y sobre todo consumidores voraces de lo que sólo $x$ Fermín ha costado sacrificio). Es posible afirmar que Conversación en la Catedral, como conjunto, es una crítica a la actitud moralista. No porque destruya la moral en una igualación agnóstica de todos sus personajes, sino porque pone de manifiesto la falacia de los pomposos programas de 'moralización' que ostentan los re: 
gímenes fascistas, bajo los cuales se esconde la eficacia en la represión de los movimientos populares. La homosexualidad de Fermín Zavala no es barata denigración de la burguesía, ni de la homosexualidad, sino un medio expresivo (por otra parte, ya conocido en otras literaturas) para romper la inmutable buena conciencia de ciertas clases sociales. (Aquí también con diferencias. En la novela es presentada de manera más positiva la figura de Fermín que la de su mujer, doña Zoila. La frustración social, profesinnal y hasta política de Santiago Zavala nos deja un sabor mer:os amargo que el monolítico triunfo del Chispas). El moralismo programático del régimen es sólo para la imagen exterior: Cayo Bermúdez, el supremo moralizador, organiza orgías en su casa de San Miguel. Fermín Zavala hace eliminar a la Musa, para eludir sus extorsiones. El moralismo es, en esta obra, un mecanismo de defensa del sistema. El rebelde, o simplemente el crítico, por parcial que sea su disconformidad, se trasforma en algo así como el asesino de la moral. El pecado es definido aquí como la rebelión.

En La ciudad y los perros, el mundo de valores-límite no ha sido creado por los mismos alumnos: ellos encuentran ya un orden establecido, en que los educadores-militares son la correa de trasmisión de lo que la sociedad ha producido, con sus desequilibrios, y de lo que, a pesar de ello, exige para el futuro. La crueldad del Jaguar es para los más pequeños un argumento de la existencia del infierno, pero al mismo tiempo él se jacta de haber enseñado a ser hombres a todos los demás. ¿O es cruel sólo porque nadie ha podido abusar de él? Alberto logra mantenerse en aquel punto medio de neutralidad que le confiere su capacidad inicialmente 'artística', sus posibilidades de defensa mediante la ironía, y sus intereses prácticos. 'No logra infundir más que la idea del valor en el Esclavo, irremediable víctima de su pusilanimidad. Alberto, sin embargo, sabe que no se trata sólo de cobardía: el cadete Arana es moralmente superior a muchos de sus compañeros. Aquí también, Arana se hubiera salvado si hubiera permanecido en la 'ciudad'. Confrontado a la conflictualidad exasperada del internado, sucumbe: y no en lucha leal. Algún 'valiente' lo elimina a traición.

El teniente Gamboa insiste en la necesidad de la disciplina: pero el capitán Garrido la contrapesa con la defensa de la audacia, de la iniciativa. Podríamos interpretar la actitud de Gamboa como los derechos del moralismo, de un mundo que funcione con perfecta coherencia. Pero Garrido advierte que esa adaptación total a las órdenes sería la destrucción de las características más valiosas del verdadero militar. En realidad, caóticas o no, las actividades de los cadetes buscan el camino de lo auténtico, de sus verdaderos derechos. La sumisión total sería como la mutilación de Cuéllar, en Los cachorros, que, tarde o temprano, conduce a la 
autodestrucción, por el camino de una liberación angustiosa, desordenada y traumática. La privación de la sexualidad, de la expresión artística o de la libertad, va a terminar en una recuperación ilusoria del tiempo perdido.

Pantaleón y las Visitadoras continúa esta temática. El capitán Pantoja es un incorregible moralista: su sentido del deber llega a ser patológico. En él la disciplina es un mito por el cual se debe sacrificar todo. Al mismo tiempo, antes de entrar en una crisis personal acerca de su actitud, recibe el castigo de sus virtudes y cualidades. Es precisamente su aceptación incondicional de la autoridad y su eficiencia lo que constituye su debilidad: pertenece él mismo de lleno a aquel mundo inmoral del que quería librar a tantos soldados 'que esperaban en él'. Como el hermano Francisco, fracasa en sus tentativas de ofrecer una liberación a la población amazónica.

La Casa Verde es la obra de Vargas Llosa en que se ve quizá con mayor claridad la condición histórica del hombre, en que los determinismos son más poderosos y esclavizadores. Aqquí el éxito es dudoso hasta en el plazo de lo trascendente. Incluso las misioneras de Sania María de Nieva contribuyen, contra sus intenciones, a asegurar el funcionamiento de la mala vida, a través de la larga mediación de la occidentálización forzada de las niñas selváticas, de su desarraigo tribal y de la desocupación que reina en las ciudades. La obra no es una distribución general de culpabilidad, ni explota los difusos mecanismos escandalísticos en aras del interés. Es más bien un análisis estructural de la íntima relación que existe entre todos los componentes del cuerpo social. No hay fácil idealización. Las niñas indias no son ni felices, $\mathrm{ni}$ totalmente respetadas en susirespectivos grupos. Por otra parte, con la construcción de la Casa Verde, Piura trata de entrar en la 'modernidad', en busca de una moralidad autónoma. El crecimiento moral bajo el signo del terror y de la represión busca su expansión en el enfrentamiento con la norma moral petrificada, la predicación severa y descarnada del Padre García, el 'quemador'. Sin embargo, la liberación es ilusoria, conflictiva. En La Casa Verde suceden delitos de todo tipo, violaciones, corrupción de memores. En la selva, Fushía niega tener propensión a negocios turbios: lo que sucede es que sin capital inicial todos los negocios son sucios.

Por otra parte, la línea que señalaba la gradual destrucción de las posibilidades expresivas, y de acción, en Los cachorros, llega a culminación en la parte final de La tía Iulia y el escribidor: la enorme energía de Pedro Camacho y su dedicación al trabajo no sólo son ineficaces para hacer de él un verdadero escritor sino aun para mantenerlo en el nivel de un productor de cultura comercializada. Hay aquí también una crisis de la homogeneidad 
lineal trabajo-rendimiento, esfuerzo-éxito, que es una de las bases teóricas de la actitud moralista. No es exagerado interpretar las borrascosas relaciones del narrador con la tía Julia como los vaivenes de la sublimación y los sacrificios de la afectividad que impone al artista una sociedad cuyo paradiama de éxito está muy lejos de los intereses de lo cultural.

\section{La fuga de la causalidad.}

Nada más normal, en contexto moralista, que las tente:ivas de escamotear la causalidad, como un elemento 'fixista' que obligaría a negar la omnipotencia de la propia voluntad o a admitir la fuerza de los determinismos. Aceptar la causalidad es ser 'reducido' en la propia estima incondicional. Esta lucidez scbre el propio ser se presenta de manera amenazadora, pues cuesta el sacrificio de la novedad, de la variedad ilimitada y sin ley; puede hasta parecer una traición al Nuevo Mundo y una adaptación incondicional a la marcha espiritual que impone el desarrollo de las sociedades industriales. La causalidad es poco menos que un estorbo en la necesidad de dominar la naturaleza y el mundo himano: introduce la exigencia de cambio y de investigación incesante, mientras destruye el equilibrio de las representaciones y ritos con las cuales se puede ob'ener lo inalcanzable. En el moralismo es siempre la voluntad lo que ocupa el lugar central: si el rito no tiene éxito, es siempre por insuficiencia moral propia o por influjo de una voluntad más poderosa. Al mismo tiempo, el recurso a lo sobrenatural $y$ a lo mágico deja intacto el sentimiento del propio valer: lo que no se alcanza pertenece a un ámbito esencialmente extraño, sobrehumano, cyilante lanimposibilidad metafísica nadie podría sentirse disminuido. La magia y la brujería mantienen así la propia imagen. El demonio y las almas en pena permiten ser siempre valientes ... en los demás casos.

En la obra de Vargas Llosa, el ideal programático de totalidad se expresa en un sondeo omnicomprensivo de los diversos niveles de la realidad peruana. No sería excesivo afirmar que la estructura estilística está al servicio de lo temático, alcanzando, por eso mismo, su plena vigencia estética. Los planos formales de lo estético y de lo moral no se agotan en esteticismo ni en machacona predicación, sino que alcanzan las dimensiones de lo moral precisamente por asumir los determinismos, en el análisis de las vertientes económica, social y política. $\odot$, desde otro punto de vista, porque asumen en plenitud la geografía y la historia, el espacio y el tiempo. Vargas Llosa denuncia más bien las tentativas de escapar a la causalidad, de reducirla a álibi o a noúmeno inconoscible. No todo puede ser aclarado pero tampoco es lícito que todo quede oculto. La causalidad implacable puede destruir 
las tradicionales apoteosis (de personas, naciones o ideas), pero puede también devolver su lugar humano a quien previamente había sido humillado. El análisis estructural de la sociedad peruana llega a su punto más alto en Conversación en la Catedral. Aquí la actividad económica queda patente en su carácter elitista e individualista $y$, por tanto, antidemocrático. No es la iniciativa privada' la que se pone en discusión, como podría pensar quien re. dujera a Fermín Zavala (la burguesía peruana) a sus fallas morales. Es su absoluta falta de partner lo que la deja al descubierto, como resultado, y causa, de regímenes antidemocráticos. El 'pueblo' no es relevante económicamente. Todo depende de la sagacidad de Fermín y de su modo de tratar a sus 'socios' norteamericanos. El mismo régimen de Odría existe por permisión del capitalismo extranjero: es puro instrumento formal de legitimidad. Como se ve, es el reino de la apariencia. La represión, en este contexto, no es sólo desahogo de los instintos sádicos de Cayo Bermúdez que, después de todo, vivía más o menos satisfecho en Chincha. Es, ante todo, la tentativa de eliminar la conciencia de la causalidad, el análisis y la acción implacables de apristas y comunistas y, a través de ellos, del pueblo. Es obvio que todo régimen antidemocrático teme ante todo la claridad acerca del or:gen de la riqueza. Ocultándola o reprimiéndola, obtiene que se difunda una causalidad sectorial, personalista, en que el capital se forma a partir de la decisión y de la voluntad de un grupo restringido. La estructura social, en consecuencia, es mantenida dentro de límites rígidos y casi inmutables. Ambrosio, Ludovico e Hipólito, a pesar de sî̉ adhesión incondicional, sólo llegarán a 'entrar en el escalafón'. La rebelión de Santiago Zavala lo desplaza hacia el proletariado, pero da ventajas a "fa" eficiencia' de su hermano el Chispas y a la granítica buena conciencia de Teté y de doña Zoila. Los estudiantes y los militantes de izquierda terminan en el exilio o enloquecidos por la tortura. Desde otra perspectiva, la fuga de la causalidad trasforma la realidad política en pura actividad volitiva: concretamente, en hipertrofia de lo conspiracional. El oportunismo degenera la actividad política a búsqueda de ventajas, el alto precio de la debilidad del país.

Los determinismos son negados también en la desmedida confianza en las posibilidades de lo axiológicamente relevante. Los valores se sostienen, ciertamente, contra todas las tentativas reduccionistas; pero ello no significa que escacen a la historia o que puedan trasformar, sin contrapesos, los mecanismos psicológicos habituales. En La ciudad y los perros, La Casa Verde y Los cachorros encontramos el análisis de este proceso de superación por decreto de los determinismos o de desmedida personalización. En La ciudad y los perros la conflictualidad social es reducida a dimensiones individuales, y se le aplica terapias voluntaristas; la 
carencia de las figuras parentales, los desequilibrios sociales y las rivalidades raciales y regionales son cubiertos mediante un acto pedagógico institucional: la entrada de algunos muchachos en un colegio militar y la aceptación (paroxística) de valores que se pretende pueden salvar a la sociedad. La internacionalización de tales valores pone en peligro la resistencia psicológica de los alumnos y hasta su vida física. En Los cachorros esta sectorialización de los valores será descrita como mutilación, es decir, como irreparable y violenta privación de una dimensión de la personalidad: a Cuéllar, como a los cadetes, le ha sido arrebatada la infancia. es decir, la posibilidad de remontarse a un tiempo originario, fundacional, en que todo estaba posibilitado hacia el futuro, a pesar de que no todo estaba permitido. Esta juventud está privada de la capacidad de ingenuidad, de juego, de irresponsabilidad. Más aún, es a ella a quien se impone la tarea de 'salvar' a una sociedad que se reconoce corrompida.

En La Casa Verde se somete a análisis la determinación cultural. La 'modernidad' avanza ilusoriamente en la fundación del prostíbulo y en la victoria sobre la moral del Padre García, sin alcanzar un auténtico dominio del propio mundo ético. La modernidad avanza, pero se frustra, en los esfuerzos del indio Jum por obtener relaciones económicas más justas. Y con mayor razón, en la acción occidentalizadora de las misioneras. Aquí el conflicto llega a un punto particularmente álgido, pues ya no se trata de lo moralmente insuficiente que da sus correspondientes frutos: aquí son el sacrificio y la rectitud los que provocan el fracaso moral (Bcnifacia-La Selvática).B Como hicimos (observar antes, no se idealiza la situación de las niñas selyáticas pero se acentúa que lo cultural no es un elemento accesorio que puede abandonarse de un día para otro. Aquí se pone en discusión incluso la confianza es. quemática en que el bien sólo puede reproducirse con sus mismas facciones. En La ciudad y los perros hay elementos paralelos: el Jaguar no termina en la cárcel, Gamboa es castigado por su rectitud.

Pantaleón y las Visitadoras y La tía Julia y el escribidor, a pesar de su heterogeneidad temática, tienen puntos de estrecho contacto: en ambas se señala la evasión de la correcta causalidad social. En la primera, la obediencia y la disciplina se vuelven, usando la terminología de Pantoja, una 'excrecencia', que se desarrolla autónomamente. La eficiencia tiene sus propias leyes y las sigue, poniendo en peligro el cuerpo social. Sin embargo, desde el punto de vista de la anécdota, es el modo de 'resolver' el problema lo que llama la atención, y produce no sólo hilaridad sino también reflexión crítica. Se trata de una solución parcial y objetivista, en que el hombre concreto es reducido a mecanismo fisiológico: no son la calidad de las relaciones humanas ni el me- 
joramiento de las condiciones de vida lo que ocupa el primer lugar sino la satisfacción de una necesidad física. Acallado el deseo (por un momento), la dinámica social corre sobre ruedas. La fuga extrema de la causalidad está representada en el movimiento heterodoxo del hermano Francisco: no llegamos a saber qué doctrina predica, fuera de un general simbolismo de la cruz y de la madera $\mathrm{y}$ de un ritual que termina en la crucifixión de seres hilmanos. Algo parecido encontramos en La tía Tulia y el escribicor, sobre todo en los capítulos pares, que trascriben los apocalíticos dramones de Pedro Camacho. Sus argumentos son elementos estabilizadores del statu quo, precisamente por su total originalidad y alejamiento de la realidad. Lo que constituye el interés de los oyentes asegura al mismo tiempo la benevolencia de los dueños: no hay a la vista peligro alquno para la tranquilidad de las clases satisfechas.

\section{La ironía como deficiencia de identidad.}

No es fácil ofrecer hipótesis acerca del origen de difusas actitudes psicológicas y modos de reaccionar. La complejidad de las situaciones y las diferencias entre los diversos grupos humanos hace siempre imprecisa y aproximativa cualquier tentativa de caracterización. Sin embargo, la acentuación de ciertos rasgos permite establecer líneas divisorias, provisionales y móviles, que nos conceden una cierta libertad en la calificación de lo observado. Podríamos decir que la existencia del adjetivo (y del adverbio) tiene su fundamento realten desplazamientos $o$ intensificaciones de matices del mundo objetivo $Y$ de la actividad sujetiva. Aquí, apoyándonos en la obra narrativa de Varaas Llosa, proponemos la interpretación de la ironía (peruana y, en cierta medida, latinoamericana) romo resultado de una deficiencia en la identidnri. No hablamos, ciertamente, de una carencia de identidad: sólo que esta identidad es todavía incompleta, no totalmente formada. Creemos que esta situación explica en parte el particular desarrollo del elemento irónico en la vida del hombre latinoamericano. No es lícito, por supuesto, llegar a una reducción psicoloqista. en que el conflicto constitutivo entre determinismo y libertad. causalidad y moralismo, tecnicismo y moralidad (que es el fundamento b́ltimo de la actitud irónica), desabareciera en la simple afirmación de 'cualidades' peculiares a los latinoamericanos. Sin embargo, el fenómeno en cuanto tal incita nuestra curiosidad y nos impulsa a un sondeo, siquiera parcial. La actitud socarrona, la burla fugaz y pluridirigida, un desmedido sentido del ridículo. confieren agilidad y ligereza a la conversación, y al pensamiento, pero les quiton eficacia, constancia y audacia en la experimentación. No podemos anotar aquí, ni siquiera a manera de hipótesis, los 
factores que contribuyen a la particular acentuación del elemento irónico en la vida del latinoamericano. Nos limitamos a los que pueden ser encontrados en la obra narrativa de Vargas Llosa. En su mundo artístico. la ironía es un recurso con diversas vicisitudes.

Hay una ironía que toma la forma de malestar y protesta que proviene del subdesarrollo. No es la pobreza como tal la que provoca la actitud irónica sino la conciencia de que se sufre un destino injusto, del cual se ven libres otros grupos humanos. Es, podríamos decir, la experiencia de la arbitrariedad del destino. Encontramos textos muy significativos en Conversación en la Catedral. La ironía es usada aquí en su sentido aristotélico, como desvalorización de sí mismo: es efecto de la sensación de retroceso, de estar perdiendo terreno. El escepticismo y, acarentemente, el cinismo repta entre los periodistas, colegas de Santiago Zavala. Carlitos envidia los tiempos de las antiguas revistas limeñas Variedares y Mundial, en que los peruanos leían a Vallejo y a Mariátegui: 'ahora nos leen a nosotros, Zavalita, qué retroceso'. Carlitos se alcoholiza sin remedio, porque 'el periodismo no es una vocación sino una frustración'. Poco antes de morir, destroza su máquina de escribir. Para sus colegas, se trata de 'defenderse del Perú como se pueda. Aquí la autoironía es ironía trágica, que sobrepasa claramente los límites de lo cómico, en que habitualmente se la clasifica.

En otras ocasiones, la ironía se lanza hasta el límite de la agresividad permitida, con la finalidad de defender la propia situación social. Véanse los casos, ya citados, de doña Zoila y sobre todo Teté y el Chispas. Las ideas progresistas de Santiago Zavala, que terminarán siquiera en un rechazo del fascismo, constituyen una amenaza para la pacífica posesión de los privilegios de la familia. A un nivel más modesto, pero a veces más tenaz, el mismo mecanismo se expresa en el resentimiento de Pochita, la esposa de Pantoja, por los sacrificios a los que la condena la 'misión secreta' de su marido. 'Te juro que al general Scavino le cortaría lo que ya sabes (jajú)'. En La ciudad y los perros la burla y la ironía tienen una función de refuerzo de la supervivencia, mediante la iniciativa en el ataque; las víctimas predilectas de la agresisidad ingeniosa son los más débiles en el sistema social: negros, indios y 'serranos'.

Hay también una ironía que surge de la deficiencia de las figuras parentales, la cual, a su vez, puede ser explicada en gran parte mediante las condiciones socioeconómicas de la respectiva sociedad. En La ciudad y los perros, los cadetes no han entrado al colegio por decisión personal, o por lo menos, con motivaciones suficientes. Ricardo Arana, el Esclavo, tiene que ser 'fogueado' mediante una disciplina rígida, porque 'las mujeres', es decir, su madre y su tía lo están arruinando con su influjo: la ironía del pa- 
dre de Arana se dirige contra ellas, y contra la capacidad educativa de las mujeres en general. El padre de Alberto, a su vez, hace alusiones que están en el límite de lo malicioso, respecto a las inclinaciones literarias de su hijo. En La Casa Verde los personajes son presentados, y revelados, en su esencia ahistórica, sin filiación conocida, enérgicos pero surgidos del paisaje. El insulto se refiere con predilección a la paternidad o a la maternidad, asi como en otros pueblos la ofensa florece en las variaciones de lo sexual o de lo coprolálico. En forma paradójica, exigida por el tono humorístico de Pantaleón y las Visitadoras, se insiste en el carácter casual de la filiación. El coronel Valdés, a una mujer de la selva que ha sido violada por los soldados, la obliga a reconocer a su agresor, para que el capellán los case: le pregunta brutalmente cuál de los soldados prefiere 'para papá de su futuro hijito'. El punto más doloroso de esta insuficiencia es quizá la figura de don Fermín Zavala: todos sabían en Lima sus debilidades, menos su hijo Santiago. 'Esta noche te hiciste hombre, Zavalita, o nunca más'. La 'traición' de la figura de su padre le quita a Santiago hasta el goce de la paternidad! a Ambrosio le hará entender que tener hijos lo considera más bien 'un deber cívico'. No es extraño, por eso, que sienta un rechazo por todo lo que representa su familia. No está en condiciones de 'seleccionar' los elementos positivos de la racionalidad burguesa. Al desheredarse voluntariamente dice al Chispas: 'Sé que harás quedar bien el nombre comercial de la familia'. No sólo la falta, sino también las insuficiencias de las figuras parentales, provocan o prolongan las situaciones conflictivas y cencuentran lexpresión en la ironía. Las dificultades de la vida familiari del capitán Pantoja son agudizadas por la tutela opresiva de su madre doña Leonor.

Desde otro punto de vista, puede ser opresiva también la rigidez del tejido social de relaciones familiares, que forma, sobre todo en los países menos industrializados y urbanizados de América Latina, una malla poco menos que irrompible. Encontramos un texto al respecto en las aventuras amorosas del narrador de La tía Julia $y$ el escribidor. La familia entera (es decir, patriarcal) participa en la conspiración para hacerlo casar por la Iglesia: el arzobispo de Lima era, 'por supuesto', pariente de ellos.

La ironía puede explicarse todavía como resultado de la de. ficiencia en la identidad moral ( $y$, obviamente, también como camino hacia ella). En Pantaleón y las Visitadoras, Vargas Llosa desarrolla lo que podríamos llamar la dimensión moral de la ironía. No se trata solamente de obtener hilaridad sobre la 'incoherencia' o la 'hipocresía' de personas e instituciones. Por debajo de ese plano corre la crítica a los conceptos tácticos y oportunistas de la moralidad: en fin de cuentas, la moral del resentimiento, del 'no poder hacer', del que es honesto por necesidad $\circ$ por 
pereza. "Cuando la opinión pública, en los pueblos de la selva, llega a conocer la existencia del servicio de visitadoras, trueca rápidamente el escándalo inicial por una actilud menos desinteresada: exigen que se extienda también a los civiles. Y encontraremos divirtiéndose con las visitadoras no sólo al general Scavino y al Sinchi sino hasta al padre Beltrán.

Universidad de Münster.

Miguel Valle

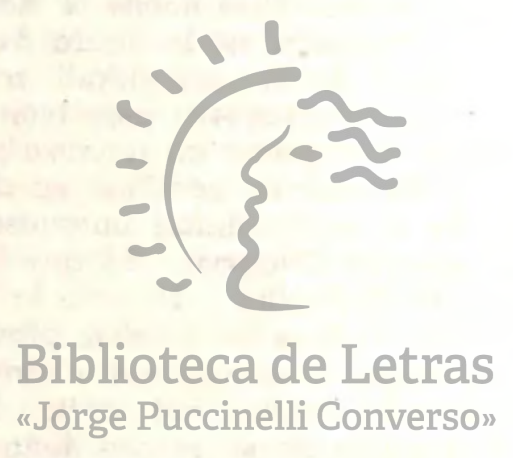

